\title{
Major diseases, extensive misuse, and high antimicrobial resistance of Escherichia coli in large- and small-scale dairy cattle farms in Jordan
}

\author{
Mohammad M. Obaidat, ${ }^{* 1}$ Alaa E. Bani Salman, ${ }^{*}$ Margaret A. Davis, $\dagger$ and Amira A. Roess $\ddagger$ \\ *Faculty of Veterinary Medicine, Jordan University of Science and Technology, Irbid, Jordan 22110 \\ †Paul G. Allen School for Global Animal Health, College of Veterinary Medicine, Washington State University, Pullman 99164-7040 \\ fDepartment of Global Health, The George Washington University, Washington, DC 20052
}

\section{ABSTRACT}

This study aimed to determine the major diseases, antimicrobial use, and resistance in commensal Escherichia coli in dairy cattle in Jordan. Forty-three (large, $\mathrm{n}=21$; small, $\mathrm{n}=22$ ) farms were surveyed. A validated questionnaire was administered to the herdsmen to elicit information about disease prevalence, antimicrobial knowledge, and antimicrobial use. In addition, fecal samples were collected from 5 lactating animals on each farm. A total of $520 \mathrm{E}$. coli isolates were tested for resistance to 12 antimicrobials. From the herdsmen's perspective, the diseases that require use of veterinary services in large and small production systems were mastitis $(51.2 \%)$, metritis $(51.2 \%)$, and enteritis (39.5\%), and the most commonly used antimicrobials were oxytetracycline and streptomycin. Dairy herdsmen $(83.7 \%)$ reported that it is easy to purchase antimicrobials without a veterinary prescription and $97.7 \%$ of them more frequently changed the antimicrobial drug rather than increasing the dose when presented with nonresponse to treatment. Escherichia coli isolates exhibited high resistance to streptomycin (47.5\%), tetracycline (45.4\%), and ampicillin (34.2\%). Less than $10 \%$ of isolates were resistant to chloramphenicol, kanamycin, gentamicin, ciprofloxacin, and ceftriaxone. Overall, 64.6 and $37.1 \%$ of the E. coli isolates exhibited resistance to $\geq 1$ antimicrobial and multidrug resistance (resistance to $\geq 3$ antimicrobial classes), respectively. The isolates exhibited 107 antimicrobial resistance profiles. This study indicates that antimicrobials are frequently misused in dairies in Jordan and that resistance among commensal E. coli toward antimicrobials of human and veterinary importance is high. Therefore, educational programs for herdsmen and enacting regulations and

Received August 10, 2017.

Accepted November 13, 2017.

${ }^{1}$ Corresponding author: mmobaidat@just.edu.jo guidelines are necessary to promote the judicious use of antimicrobials in dairy animals in Jordan.

Key words: antibiotics, ruminant, rural, developing countries

\section{INTRODUCTION}

The emergence of antimicrobial resistant pathogens compromises the effectiveness of clinical treatment of human and animal infectious diseases and has major global public health and negative economic impacts (File et al., 2014; Friedman et al., 2016). Inappropriate antimicrobial use in human and veterinary medicine selects for resistance in bacterial pathogens, and some of these pathogens are zoonotic and can be transmitted from animals to humans (Leverstein-van Hall et al., 2011; Landers et al., 2012). Antimicrobial resistance is a worldwide problem and exists in both resourcerich and resource-poor settings. This problem, however, might be more severe in developing countries due to less-restricted availability and use of antimicrobials in food animal production (WHO, 2014).

Studying antimicrobial resistance in commensal bacteria is valuable as these bacteria can serve as reservoirs for resistance genes and can transfer these genes to pathogenic bacteria (DeFrancesco et al., 2004; EFSA, 2008). Antimicrobial resistance in commensal bacteria is positively correlated with local antimicrobial selective pressure and may be a risk for developing antimicrobial resistance in pathogenic bacteria (Hao et al., 2014). Thus, frequent monitoring of antimicrobial resistance in bacterial isolates from animals can help detect emerging antimicrobial-resistant phenotypes in commensal and pathogenic bacteria within the food production chain.

Concerns about antimicrobial resistance led to the launching of surveillance and monitoring programs in resource-rich countries such as the United States, Canada, Denmark, France, Sweden, and Norway (NORM/ NORM-VET, 2010; RESAPATH, 2012; CIPARS, 2013; DANMAP, 2014; SWEDRES/SWEDVARM, 
2014; ECDC, 2015; NARMS, 2015). However, data on nonprescription antimicrobial treatment of livestock in resource-poor countries such as Jordan are lacking. Although Jordan relies on beef importation to satisfy its domestic meat demand, dairy cattle are a major component of the Jordanian animal industry and 2 dairy production systems exist in Jordan: large and small scale. Large intensive production systems use modern management practices with zero-grazing and minimum separation between lactating and nonlactating cows in the same farm. These farms are predominantly located in the Al-Dulial area, which produces around $50 \%$ of the country's milk (DoS, 2015). Small-scale production systems are scattered in different regions of Jordan, mainly in the Highland area. In this system, cows are housed in small, traditional brick barns, with no separation among cows, and herdsmen use more traditional management practices than in the large systems. Both systems raise Holstein-Friesian dairy cows and together contribute US\$160 million annually to the national gross domestic product (DoS, 2015).

To better define the use of antimicrobials in dairy production systems in Jordan, we surveyed dairy farms and sampled dairy cattle feces to investigate disease incidence and antimicrobial treatment practices and to estimate the prevalence of antimicrobial resistance among fecal Escherichia coli. In addition, we compared large and small dairy farms with respect to the above parameters.

\section{MATERIALS AND METHODS}

\section{Farm and Animal Selection}

Forty-three farms (21 large farms from intensive production systems in Al-Dulail area and 22 small farms from small-scale production systems in the Highlands) were selected and visited in 2015. Large production systems had $>50$ cows per farm, whereas the small-scale production systems had $<50$ cows per farm.

From each farm, 5 lactating cows that were 2 to $5 \mathrm{yr}$ of age and had no antimicrobial treatment within the last 2 wk were eligible for inclusion and sampled. In each farm, the number of cows from a sampling frame of all cows meeting these inclusion criteria was divided by 5 (total number of cows $/ 5=k$ ) and every $k$ th cow was sampled. To prevent selection bias, neither individual disease history nor milk production performance was known for the sampled animals. From our pretest activities, we found that herdsmen were unwilling to allow researchers to sample more than about 5 cows because they did not want researchers to spend long periods of time on their farms.

\section{Sampling Approach}

In each area, designated and trained practicing veterinarians were recruited to assist with questionnaire data and sample collection because they have strong ties with the herdsmen (their clients), are from the same community, and speak the same dialect. This approach allowed access to the selected farms and helped ensure the accuracy of the questionnaire. To encourage voluntary participation from herdsmen, government veterinarians did not participate in the study. The herdsmen were briefed about the study objectives, assured that the study was only for research purposes, and that any generated data from their specific farm would be available to them upon request. Consent to conduct interviews and collect samples was obtained from the herdsman at each farm before beginning the study.

\section{Questionnaire}

A modified questionnaire based on Redding et al. (2014) was developed and used in this study to interview the herdsmen. The questionnaire was developed in Arabic, and then pretested with a convenience sample of herdsmen from 3 large and 3 small farms. Necessary revisions were made before the questionnaire was finalized. The repeatability of the questionnaire was examined by asking the same farmers the questions in 2 ways: during a face-to-face interview and by phone call. Then, repeatability was determined by calculating the agreement between answers to 4 questions: (1) What do you do for animals that receive antimicrobial treatment? (2) Do you obtain prescriptions before administering antimicrobials to your animals? (3) Does the veterinarian examine the diseased animals before prescribing antimicrobials? (4) Do you use antimicrobials for growth promotion? The kappa scores for each question were 0.94 (very good), 0.90 (very good), 0.86 (very good), and 0.83 (very good), respectively. The questionnaire was divided into 3 major sections to capture overall (1) farm management, (2) diseases of concern, and (3) antimicrobial use. The herdsmen were also asked to list the importance of several factors that they use before choosing an antimicrobial, including price, quality, brand, packaging, ease of acquisition, experience with the drug, and recommendation of the veterinarian or drug store vendor.

\section{Commensal E. coli Isolation and Identification}

Fecal samples (10 g) were collected with a clean rectal sleeve from the distal rectum of each individual cow 
and placed into sterile containers that were labeled and kept on ice until delivered to the Food Hygiene Laboratories, Faculty of Veterinary Medicine, Jordan University of Science and Technology (Irbid) for analysis. Samples from 5 animals were taken from each farm and labeled with a unique identifier. A new rectal sleeve was used for each animal to prevent cross-contamination among the samples.

Escherichia coli was isolated from the fecal samples using a standard protocol as follows. Briefly, $10 \mathrm{~g}$ of each fecal sample was mixed with $225 \mathrm{~mL}$ of $0.1 \%$ peptone water. Then, $20 \mathrm{~mL}$ of the fecal mixture was mixed with $20 \mathrm{~mL}$ of double-strength MacConkey broth (Oxoid Ltd., Basingstoke, UK) and incubated at $35^{\circ} \mathrm{C}$ for $24 \mathrm{~h}$. The broth culture was then streaked onto MacConkey agar (Oxoid) and incubated at $35^{\circ} \mathrm{C}$ for 24 h. Suspected E. coli (pink) colonies were streaked onto eosin methylene blue plates (Oxoid) and incubated at $35^{\circ} \mathrm{C}$ for $24 \mathrm{~h}$. Metallic green colonies were considered presumptive $E$. coli and were streaked onto trypticase soy agar (Oxoid) and tested for indole and oxidase production. Suspect (indole-positive and oxidase-negative) isolates were confirmed by PCR targeting the E. coli translation elongation factor EF-Tu (tuf) gene using the same primers and cycling conditions as previously described (Maheux et al., 2009). Confirmed E. coli isolates were banked in trypticase soy broth with $20 \%$ buffered glycerol at $-70^{\circ} \mathrm{C}$ for later antimicrobial resistance testing.

\section{Antimicrobial Susceptibility Testing}

Pure frozen cultures were grown on trypticase soy agar overnight at $37^{\circ} \mathrm{C}$ and adjusted to a $0.5 \mathrm{McF}$ arland turbidity in 5 -mL sterile normal saline tubes. Isolates were screened for susceptibility to a panel of 12 antimicrobials on Mueller-Hinton agar (Oxoid) by the disk diffusion method, as described by the National Committee for Clinical and Laboratory Standards (CLSI, 2014) guidelines. The following disks (Oxoid) were used: $\beta$-lactams (ampicillin, $10 \mu \mathrm{g}$; amoxicillin-clavulanic acid, $30 \mu \mathrm{g}$; cephalothin, $30 \mu \mathrm{g}$; and ceftriaxone, $30 \mu \mathrm{g}$ ), aminoglycosides (gentamicin, $10 \mu \mathrm{g}$; streptomycin, 10 $\mu \mathrm{g}$; and kanamycin, $50 \mu \mathrm{g}$ ); quinolones (ciprofloxacin, 5 $\mu \mathrm{g}$; nalidixic acid, $30 \mu \mathrm{g}$ ), phenicols (chloramphenicol, $30 \mu \mathrm{g}$ ), tetracyclines (tetracycline, $30 \mu \mathrm{g}$ ), and folate pathway inhibitors (sulfamethoxazole-trimethoprim, $25 \mu \mathrm{g}$ ). Isolates with intermediate susceptibility to the tested antimicrobials were considered "susceptible" for analysis purposes. Escherichia coli ATCC 25922 and Staphylococcus aureus ATCC 29213 were used as reference strains for the disk diffusion method quality control. An isolate was considered resistant when it was resistant to $\geq 1$ antimicrobials and multidrug resistant when it was resistant to $\geq 3$ classes of antimicrobials (Magiorakos et al., 2012).

\section{Data Analysis}

Data were entered in Excel (Microsoft Corp., Redmond, WA) and analyzed using MedCalc for Windows (version 17.9; MedCalc Software, Ostend, Belgium). Chi-squared and Fisher's exact tests were used as appropriate to assess the differences in each variable of interest (antimicrobial resistance outcome or questionnaire variables) independently between large and small farms (Pagano and Gauvreau, 2000; Deeks and Higgins, 2010). Odd ratios were used to determine the association between farm-level antimicrobial use and resistance among fecal $E$. coli isolates.

\section{RESULTS}

\section{Disease Incidence and Use of Veterinary Services}

The response rate for this study was $98 \%$, with only one farmer declining to participate. Overall, $51.2 \%$ of the dairy herdsmen reported clinical mastitis, and the same number reported metritis as frequent animal health concerns that require veterinary service, followed by dystocia (41.9\%), enteritis $(39.5 \%)$, and respiratory infections (27.9\%; Table 1). However, herdsmen in large dairy farms reported mastitis and metritis more than herdsmen in small farms and this was statistically significant $(P=0.01)$. Lameness, left-displaced abomasum, and bloat were also reported by herdsmen in large dairy farms, and dystocia was reported by $81.1 \%$ of herdsmen in small dairy farms (Table 1). We detected no significant differences between large and small farms in reporting enteritis and pneumonia. All of the dairy herdsmen reported using veterinary services; $19 \%$ of the large dairy farms and none of the small farms reported having a resident veterinarian (Table 1 ).

\section{Acquisition of Antimicrobials}

Antimicrobials were obtained from 3 sources in Jordan: veterinary drug stores, Ministry of Agriculture (MOA) offices, and practicing veterinarians. Among the herdsmen $(\mathrm{n}=43)$ interviewed, $79.1 \%$ reported obtaining antimicrobials from veterinary drug stores, $27.9 \%$ from field veterinarians, and $16.3 \%$ from MOA offices. However, one large farm reported obtaining antimicrobials directly from the manufacturers. In addition, $83.7 \%$ of herdsmen reported that it was easy to purchase antimicrobials without a veterinary 
Table 1. Response (percentages) of dairy herdsmen to questions regarding veterinary services for specific diseases in Jordan by production system in $2015^{1}$

\begin{tabular}{|c|c|c|c|c|}
\hline Practice/response & $\begin{array}{l}\text { Large system } \\
\quad(\mathrm{n}=21)\end{array}$ & $\begin{array}{l}\text { Small system } \\
\quad(\mathrm{n}=22)\end{array}$ & $\begin{array}{l}\text { All farms } \\
(\mathrm{n}=43)\end{array}$ & $P$-value \\
\hline Do you use veterinary services? & 100 & 100 & 100 & 0.98 \\
\hline \multicolumn{5}{|l|}{ When do you use veterinary services? } \\
\hline Metritis & 71.4 & 31.8 & 51.2 & 0.01 \\
\hline Enteritis & 38.1 & 40.9 & 39.5 & 0.65 \\
\hline Pneumonia & 33.3 & 22.7 & 27.9 & 0.44 \\
\hline Bloat & 28.6 & 0 & 14.0 & 0.05 \\
\hline Dystocia & 0 & 81.8 & 41.9 & 0.00 \\
\hline Do you have a resident veterinarian on the farm? & 19.0 & 0 & 9.3 & 0.11 \\
\hline \multicolumn{5}{|c|}{$\begin{array}{l}\text { Does the veterinarian examine the diseased animals before } \\
\text { prescribing antimicrobials? }\end{array}$} \\
\hline Always & 47.6 & 45.5 & 46.5 & 0.89 \\
\hline Sometimes & 52.4 & 54.5 & 53.5 & 0.89 \\
\hline \multicolumn{5}{|c|}{$\begin{array}{l}\text { Do you obtain prescriptions before administering antimicrobials } \\
\text { to your animals? }\end{array}$} \\
\hline
\end{tabular}

${ }^{1}$ Percentages do not sum to $100 \%$ in a given column or row because farmers reported $>1$ disease.

prescription. Among herdsmen, 46.5\% reported that the veterinarian always examined the animals before antimicrobial treatment, and $32.6 \%$ reported that they always obtained a prescription. However, $53.5 \%$ of the herdsmen reported that their veterinarian sometimes examined the animal before antimicrobial treatment and $67.4 \%$ reported that they usually obtained prescriptions before purchasing antimicrobials (Table 1).

The herdsmen considered different factors when purchasing antimicrobials but, in most cases $(60.4 \%)$, price was the most important factor, followed by veterinary recommendations, and then experience. Packaging was the least important factor considered.

\section{Antimicrobial Use}

The most commonly used antimicrobials on the dairy farms were oxytetracycline, penicillin $\mathrm{G}$ with streptomycin, gentamicin, and sulfamethoxazole-trimethoprim. Less commonly used antimicrobials were amoxicillin,

Table 2. Antimicrobials used (in descending percentages) for specific diseases in dairy farms in Jordan by production system in $2015^{1}$

\begin{tabular}{|c|c|c|c|c|c|}
\hline Disease & Used antimicrobial & Large system & Small system & All farms & $P$-value \\
\hline \multirow{5}{*}{ Mastitis } & Amoxicillin & 81.3 & 58.8 & 69.7 & 0.17 \\
\hline & Gentamicin & 37.5 & 47.1 & 42.4 & 0.58 \\
\hline & Amoxicillin-clavulanic acid & 12.5 & 0 & 6.1 & 0.26 \\
\hline & Spectinomycin & 6.3 & 5.9 & 6.1 & 0.96 \\
\hline & Marbofloxacin & 18.8 & 5.9 & 12.2 & 0.28 \\
\hline \multirow{3}{*}{ Metritis } & Oxytetracycline & 0 & 16.7 & 5.9 & 0.28 \\
\hline & Gentamicin & 0 & 16.7 & 5.9 & 0.28 \\
\hline & Marbofloxacin & 0 & 16.7 & 5.9 & 0.28 \\
\hline \multirow{3}{*}{ Enteritis } & Sulfamethoxazole-trimethoprim & 100 & 95.0 & 94.1 & 0.66 \\
\hline & Marbofloxacin & 7.7 & 10.0 & 2.9 & 0.82 \\
\hline & Oxytetracycline & 0 & 5.0 & 2.9 & 0.66 \\
\hline Pneumonia & Oxytetracycline with tylosin & 37.5 & 19.0 & 27.0 & 0.22 \\
\hline
\end{tabular}

${ }^{1}$ Percentages do not sum to $100 \%$ in a given column or row because some farmers might report $>1$ antimicrobial. Percentages equal the number of times the antimicrobial was used divided by the number of times the disease was reported. 
Table 3. Percentages of specific antimicrobial uses in sampled Jordanian dairy farms by production system in 2015

\begin{tabular}{|c|c|c|c|c|}
\hline Practice/response & $\begin{array}{l}\text { Large system } \\
\quad(\mathrm{n}=21)\end{array}$ & $\begin{array}{l}\text { Small system } \\
\quad(\mathrm{n}=22)\end{array}$ & $\begin{array}{l}\text { All farms } \\
(\mathrm{n}=43)\end{array}$ & $P$-value \\
\hline Which antimicrobials do you use for growth promotion? & 23.8 & 9.1 & 16.3 & 0.21 \\
\hline Oxytetracycline & 14.3 & 0 & 3 & 0.17 \\
\hline Amoxicillin & 4.7 & 0 & 1 & 0.47 \\
\hline Yeast & 0 & 4.7 & 1 & 0.51 \\
\hline Oxytetracycline with multivitamin & 0 & 4.7 & 1 & 0.51 \\
\hline Yes, when other animals on the farm are sick & 4.8 & 100 & 53.5 & 0.00 \\
\hline
\end{tabular}

tylosin, marbofloxacin, and ceftiofur. Use of tilmicosin, alamycin, and lincomycin/spectinomycin was rarely reported (Table 2).

The dairy cattle diseases most commonly treated with antimicrobials on Jordanian dairy farms were mastitis, metritis, enteritis, and respiratory diseases. Mastitis was treated with intramammary infusions of amoxicillin $(69.7 \%)$, followed in frequency by parenteral administration of oxytetracycline $(60.6 \%)$ and gentamicin (42.4\%). Oxytetracycline was used significantly more frequently $(P \leq 0.05)$ on large than on small farms (Table 2). In general, metritis was primarily treated with ceftiofur $(75 \%$ of the cases) and in some cases with tylosin (37.5\%). Enteritis was treated with antimicrobials and in most cases by sulfamethoxazoletrimethoprim (94.1\%). Respiratory diseases, including pneumonia, were treated with antimicrobials; the 3 major antimicrobials used were oxytetracycline (24.3\%), oxytetracycline with tylosin $(27.0 \%)$, and marbofloxacin $(32.4 \%)$. Other antimicrobials were rarely used in treating the 4 major diseases outlined in Table 2.

Antimicrobials were used primarily for therapeutic purposes; however, a few $(16.3 \%)$ of the herdsmen reported using antimicrobials for growth promotion in calves, including oxytetracycline $(7.0 \%)$ and sulfa- methoxazole-trimethoprim (7.0\%). The latter practice was significantly more frequent in the large dairy farms than on the small farms. On the other hand, $90.7 \%$ of the herdsmen reported the use of antimicrobials for prevention, specifically for dry cow therapy (51.2\%), and prophylactically when other animals are sick in the farm (53.5\%; Table 3). Large dairy farms in Al-Dulail practiced dry cow therapy $(76.2 \%)$ significantly more frequently than the farms in small-scale production systems $(27.3 \%)$. Interestingly, all farms in the small-scale production systems reported administering antimicrobials to healthy cows prophylactically when other cows were sick; however, very few herdsmen reported this practice in the large production systems (Table 3 ).

\section{Management of Antimicrobial Treatments}

Most herdsmen (74.4\%) reported marking recently treated animals for identification, but this was significantly more frequent among large farms than small farms. In general, $40.9 \%$ of herdsmen reported milking treated animals last. Most herdsmen (97.7\%) reported changing the antimicrobial, rather than increasing the dose, when it did not appear to be effective before completing the treatment course. Most (95.3\%) herdsmen

Table 4. Percentage of antimicrobial administration practices in sampled dairy cattle farms in Jordan by production system in 2015

\begin{tabular}{|c|c|c|c|c|}
\hline Practice/response & $\begin{array}{l}\text { Large system } \\
\quad(\mathrm{n}=21)\end{array}$ & $\begin{array}{l}\text { Small system } \\
\quad(\mathrm{n}=22)\end{array}$ & $\begin{array}{r}\text { All farms } \\
(\mathrm{n}=43)\end{array}$ & $P$-value ${ }^{1}$ \\
\hline \multicolumn{5}{|c|}{ What do you do for animals that receive antimicrobials? } \\
\hline Milked last & 9.5 & 40.9 & 25.6 & 0.03 \\
\hline \multicolumn{5}{|c|}{ If an antimicrobial does not work, what do you do? } \\
\hline Change the antimicrobial & 95.2 & 100.0 & 97.7 & 0.47 \\
\hline Increase the dose & 4.8 & 0 & 2.3 & 0.47 \\
\hline Throw away for $4 \mathrm{~d}$ & 9.5 & 0 & 4.3 & 0.27 \\
\hline
\end{tabular}

${ }^{1}$ Fisher's exact test. 
Table 5. Antimicrobial resistance percentage (in descending order) among Escherichia coli isolated from dairy cattle fecal samples in Jordan in 2015, by production system

\begin{tabular}{|c|c|c|c|c|}
\hline Antimicrobial (breakpoint, mm) & $\begin{array}{l}\text { Large system } \\
\quad(\mathrm{n}=207)\end{array}$ & $\begin{array}{l}\text { Small system } \\
\quad(\mathrm{n}=313)\end{array}$ & $\begin{array}{l}\text { All farms } \\
(\mathrm{n}=520)\end{array}$ & $P$-value ${ }^{1}$ \\
\hline Streptomycin $(\leq 11)$ & 54.1 & 43.1 & 47.5 & 0.01 \\
\hline Tetracycline $(\leq 11)$ & 45.5 & 45.4 & 45.4 & 0.99 \\
\hline Ampicillin $(\leq 13)$ & 28.9 & 37.7 & 34.2 & 0.04 \\
\hline Cefalothin $(\overline{\leq} 14)$ & 20.8 & 29.4 & 26.0 & 0.03 \\
\hline Amoxicillin-clavulanic acid $(\leq 13)$ & 14.0 & 21.7 & 18.7 & 0.03 \\
\hline Sulfamethoxazole-trimethoprim $(\leq 10)$ & 23.7 & 9.9 & 15.4 & 0.00 \\
\hline Nalidixic acid $(\leq 13)$ & 13.0 & 11.5 & 12.1 & 0.60 \\
\hline Chloramphenicol $(<12)$ & 11.1 & 7.7 & 9.0 & 0.18 \\
\hline Kanamycin $(\leq 13)$ & 10.1 & 7.7 & 8.6 & 0.33 \\
\hline Gentamicin $(\leq 12)$ & 5.8 & 2.9 & 4.0 & 0.10 \\
\hline Ciprofloxacin $(\leq 15)$ & 4.8 & 3.4 & 3.8 & 0.46 \\
\hline Ceftriaxone $(\leq 19)$ & 2.4 & 1.9 & 2.1 & 0.70 \\
\hline Resistant to $\geq 1$ antimicrobial & 69.1 & 62.0 & 65.6 & 0.10 \\
\hline Resistant to $\geq 3$ classes of antimicrobials & 36.7 & 37.4 & 37.1 & 0.88 \\
\hline
\end{tabular}

${ }^{1}$ Chi-squared $P$-value.

also reported feeding the milk of treated cows to calves for 3 to $5 \mathrm{~d}$ rather than discarding it (Table 4).

\section{Antimicrobial Resistance of Commensal E. coli}

All farms, both large and small, had at least one animal carry antibiotic-resistant E. coli. However, 89.5 and $89.1 \%$ of individual animals in large and small farms; respectively, shed antibiotic-resistant E. coli. A total of $520 \mathrm{E}$. coli isolates were confirmed by PCR and tested for antimicrobial resistance. The most frequent resistance phenotypes among the $E$. coli isolates in this study included resistance to streptomycin (47.5\%), tetracycline (45.4\%), and ampicillin (34.2\%). Fewer than $10 \%$ of isolates were resistant to chloramphenicol, kanamycin, gentamicin, ciprofloxacin, or ceftriaxone.
Overall, $65.6 \%$ of $E$. coli isolates exhibited resistance to at least one antimicrobial and $37.1 \%$ of the isolates exhibited multidrug resistance (Table 5).

Several unique multidrug resistance (MDR) profiles ( $\mathrm{n}=107)$ were exhibited by the $E$. coli isolates - 78 and 68 profiles from large- and small-scale production systems, respectively. Thirty-nine profiles were shared between the 2 production systems and are presented in Supplemental Table S1 (https://doi.org/10.3168/ jds.2017-13665). Overall, the most common resistance profiles were cephalothin $(\mathrm{n}=39)$, streptomycin $(\mathrm{n}=$ 37), ampicillin-amoxicillin-clavulanic acid-tetracyclinestreptomycin $(\mathrm{n}=23)$, and ampicillin-tetracyclinestreptomycin $(\mathrm{n}=23)$. Diverse resistance profiles were detected within the same farm and by size of farm (supplementary table). Moreover, we found no clear

Table 6. Association between farm-level $(\mathrm{n}=43)$ antimicrobial use and resistance among fecal Escherichia coli isolates $(\mathrm{n}=520)$ in dairy farms in $\operatorname{Jordan}^{1}$

\begin{tabular}{|c|c|c|c|c|c|c|}
\hline \multirow[b]{2}{*}{ Antibiotic } & \multicolumn{2}{|c|}{$\begin{array}{l}\text { Farms (no.) with } \\
\text { resistant isolates }\end{array}$} & \multicolumn{2}{|c|}{$\begin{array}{l}\text { Farms (no.) without } \\
\text { a resistant isolate }\end{array}$} & \multirow[b]{2}{*}{$P$-value } & \multirow[b]{2}{*}{ Odds ratio $(95 \% \mathrm{CI})$} \\
\hline & $\begin{array}{c}\text { Using } \\
\text { antimicrobial }\end{array}$ & $\begin{array}{c}\text { Not using } \\
\text { antimicrobial }\end{array}$ & $\begin{array}{c}\text { Using } \\
\text { antimicrobial }\end{array}$ & $\begin{array}{c}\text { Not using } \\
\text { antimicrobial }\end{array}$ & & \\
\hline Ampicillin & 0 & 39 & 0 & 4 & 0.29 & $0.11(0.002-6.47)$ \\
\hline Amoxicillin-clavulanic acid & 2 & 30 & 0 & 11 & 0.69 & $1.89(0.08-42.32)$ \\
\hline Cefalothin & 0 & 35 & 0 & 8 & 0.48 & $0.24(0.004-12.95)$ \\
\hline Sulfamethoxazole-trimethoprim & 31 & 6 & 5 & 1 & 0.98 & $1.03(0.10-10.50)$ \\
\hline Streptomycin & 22 & 20 & 1 & 0 & 0.55 & $0.37(0.01-9.49)$ \\
\hline Kanamycin & 0 & 26 & 0 & 17 & 0.84 & $0.66(0.01-34.86)$ \\
\hline Gentamicin & 11 & 6 & 17 & 9 & 0.96 & $0.97(0.27-3.50)$ \\
\hline Ciprofloxacin & 0 & 17 & 0 & 26 & 0.84 & $1.51(0.03-79.93)$ \\
\hline Nalidixic acid & 0 & 31 & 0 & 12 & 0.65 & $0.40(0.01-21.12)$ \\
\hline Chloramphenicol & 0 & 29 & 0 & 14 & 0.73 & $0.50(0.01-26.05)$ \\
\hline
\end{tabular}

${ }^{1}$ Where zeros caused problems with computation of the odds ratio or its standard error, 0.5 was added to all cells (a, b, c, d in the $2 \times 2$ table) (Pagano and Gauvreau, 2000; Deeks and Higgins, 2010). 
association between the use of and microbial resistance to a given antimicrobial (Table 6).

\section{DISCUSSION}

This study provides critical information regarding the antimicrobials used in Jordanian dairies. The most common diseases treated with antimicrobials in these dairies (in descending order) were mastitis, metritis, and enteritis. Interestingly, some of these diseases; specifically enteritis, can be caused by pathogens other than bacteria, such as parasites and viruses. Redding et al. (2014) reported the use of antiparasitics and antibiotics for treating diarrhea cases in small farms in Peru, but noted that the antiparasitics might be used to treat bacterial and viral diarrhea causes, which would be ineffective and exacerbate the drug-resistant fascioliasis in Peru. Mastitis in Jordanian dairies is treated with oxytetracycline, amoxicillin, and sometimes gentamicin, which is a critically important antimicrobial for human medicine (WHO, 2012) and not approved for use in dairy cattle in the United States (Smith et al., 2005). Metritis is mostly treated with ceftiofur, which is the same as in the United States (Galvão, 2012). The use of this antimicrobial is approved and has no milk withdrawal period and a short or no meat withdrawal period (Galvão, 2012). Although foot rot is a problem in US dairy cattle (Sawant et al., 2005), it was not reported to be a problem in Jordanian dairies, which is likely due to the drier climate.

This study showed that a limited number of antimicrobial classes are used in Jordanian dairies; and generally, oxytetracycline and streptomycin (critically important antimicrobials) are the most commonly used. These 2 antimicrobials are the most frequently used in the United States and Japan as well (Sawant et al., 2005; Harada et al., 2006; Parveen et al., 2006), and oxytetracycline is the most commonly used in small farms in Peru (Redding et al., 2014). Tetracyclines, sulfonamides, and $\beta$-lactams are the most commonly used in Europe (NORM/NORM-VET, 2010; DANMAP, 2014; Merle et al., 2014; SWEDRES/SWEDVARM, 2014). Other studies in resource-poor countries reported a similar limited number of antimicrobial classes for treating animals in Costa Rica, Sudan, and Kenya (Roderick et al., 2000; Luna-Tortos et al., 2006; Eltayb et al., 2012).

Antimicrobial use in lactating cows could lead to residues in milk, which can have adverse public health, dairy product manufacturing, and economic effects. This risk can be reduced by marking, milking last, and discarding the milk of treated cows following the recommended withdrawal period for each antimicrobial (Spiegel et al., 2013). In our study, $74.4 \%$ of herds- men marked their treated animals and $25.6 \%$ milked those animals last. Although this finding suggests that herdsmen are following correct practices, they might do this because their milk cannot be used to make fermented dairy products (antimicrobial residues slow the fermentation process by inhibiting the starter culture). However, most herdsmen used a shorter withholding period of 3 to $5 \mathrm{~d}$, which is less than the mandated withdrawal period for the widely used antimicrobial oxytetracycline. Herdsmen from small farms sell their milk to small dairy shops, which are numerous and scattered throughout the country. These dairy shop owners generally have little knowledge of the adverse effect of antimicrobial residues on human health; rather, they focus on whether the milk ferments or not. The large dairy farms, however, sell their milk to large dairy plants that check physical characteristics of the milk, including specific gravity, $\mathrm{pH}$, fat percentage, and, sometimes, antibiotic residues for antibiotics that are important from the point of view of processing. Most herdsmen $(95.3 \%)$ fed milk from treated cows to other calves on the farm for 3 to $5 \mathrm{~d}$ after treatment. A similarly high use of this practice was reported in England and Wales, where $65.4 \%$ of herdsmen fed mastitic milk to calves (Brunton et al., 2014). The same scenario was reported in Sweden, where 56 and $79 \%$ of herdsmen fed milk to calves during the course of antimicrobial treatment and during the milk withdrawal period, respectively (Duse et al., 2013). This practice is associated with shedding cefotaximase $\left(C T X_{M}\right)$-positive $E$. coli for a long period in calves (Brunton et al., 2014), as well as shedding quinolone-resistant E. coli (Duse et al., 2015).

The frequently used antimicrobials in dairy farms in Jordan are of veterinary importance (OIE, 2015); however, some herdsmen (6\%) reported using spectinomycin, which is not recommended for dairy cattle older than 20 mo because the withdrawal period of this antimicrobial has not been established (FDA-CVM, 2015).

Jordanian dairy herdsmen reported changing an antimicrobial when an animal did not respond to it during the course of treatment. Switching antimicrobials has been described in Peru as well (Redding et al., 2014), where $64.6 \%$ of the herdsmen administered a different antimicrobial and $16.9 \%$ increased the dose when an animal did not respond to initial treatment. The practice of using antimicrobials below or above the recommended doses was also reported in dairies in Switzerland (Gonzalez et al., 2010) and in veal calves in Belgium (Pardon et al., 2012).

In our study, a high percentage $(64.6 \%)$ of the E. coli isolates exhibited resistance to at least one antimicrobial. In contrast, lower percentages $(<20 \%)$ were reported in dairy cattle of resource-rich countries including the United States, Germany, and Denmark (Lundin 
et al., 2008; Kaesbohrer et al., 2012; DANMAP, 2014). In the current study, the MDR profiles included 2 common profiles; resistance to ampicillin, tetracycline, and streptomycin (23 isolates $=21.5 \%$ of the MDR isolates) and resistance to these 3 antimicrobials plus sulfamethoxazole-trimethoprim (12 isolates $=11.2 \%$ of the MDR isolates), amoxicillin-clavulanic acid (23 isolates $=21.5 \%$ of the MDR isolates), and amoxicillinclavulanic acid and cephalothin (14 isolates $=13.1 \%$ of the MDR isolates). The ampicillin-tetracycline-streptomycin resistance pattern has been reported by other researchers in different locations (White et al., 2000; Lim et al., 2007; Alexander et al., 2010; Kaesbohrer et al., 2012). This pattern might be associated with frequent exposure to minimal levels of tetracycline, often in combination with chloramphenicol (Blake et al., 2003), and linked to transferable high-molecular-weight plasmids (Karczmarczyk et al., 2011).

Almost half of the isolates (45.4\%) exhibited resistance to tetracycline in this study. Several studies in multiple worldwide locations reported frequent resistance to tetracycline among $E$. coli isolates (Teshager et al., 2000; Sayah et al., 2005; Lim et al., 2007; Lundin et al., 2008). The extensive use of tetracycline in human and veterinary medicine is attributed to their low cost, having few side effects and growth-promotion properties (Chopra and Roberts, 2001). Using tetracycline to promote growth is performed in Jordan dairies for treating calves and is proven to augment tetracycline resistance (Alexander et al., 2010; Love et al., 2011; Marshall and Levy, 2011; Mirzaagha et al., 2011). The use of antimicrobials for growth promotion is banned in European countries (Maron et al., 2013). Moreover, the reported use of ceftiofur in Jordanian dairies can contribute to the high resistance to tetracycline because the use of ceftiofur can co-select for and facilitate co-amplification of $E$. coli that exhibit co-resistance to tetracycline (Lowrance et al., 2007; Alali et al., 2009).

Considerable resistance to chloramphenicol was found in this study, despite no reported use of this antimicrobial in dairy farms. Similar findings were reported in Japan (Lim et al., 2007) and Korea (Harada and Asai, 2010). This might be attributed to co-selection of resistant determinants from using other antimicrobials (Bischoff et al., 2002; Harada and Asai, 2010) and to co-resistance with quinolone and nalidixic acid (Bialek et al., 2010). In addition, resistance to tetracycline can be transferred in $E$. coli due to the genetic linkage among their resistance genes (Bischoff et al., 2002).

A moderate proportion (26\%) of the isolates exhibited resistance to cephalothin (a first-generation cephalosporin) but fewer (3.8\%) exhibited resistance to ceftriaxone (a third-generation cephalosporin). The resistance to ceftriaxone, despite no reports of its use in dairy farms in this study, might be attributed to the wide use of ceftiofur-using ceftiofur can co-select for resistance to ceftriaxone (Tragesser et al., 2006). This led the US Food and Drug Administration to limit extra-label use of cephalosporin antimicrobials in cattle, chickens, swine, and turkeys (FDA-DHHS, 2012). Therefore, continuous monitoring for resistance to third- and fourth-generation cephalosporins is warranted in Jordan because these agents are critically important antimicrobials in human medicine (WHO, 2012) and their resistance can be disseminated through the transfer of mobile genetic elements from animals to humans.

Resistance to fluoroquinolones was relatively infrequent (ciprofloxacin $=3.8 \%$ ) among the E. coli dairy cattle isolates in this study but high enough to cause public health concern as this class of antimicrobials is of medical importance. Similarly low percentages (less than $2 \%$ ) of fluoroquinolone resistance were reported in Korea, Italy, Finland, and Sweden (Harada and Asai, 2010) and none were reported in Canada, France, Denmark, Germany, and Australia (Harada and Asai, 2010). The reported resistance to fluoroquinolones in the current study might be attributed to the extensive use of tetracycline because resistance to fluoroquinolones in multi-antimicrobial resistance isolate can be co-selected by the use of tetracyclines (Asai et al., 2007). Moreover, due to their critical importance in human medicine (WHO, 2012), the use of fluoroquinolones in veterinary medicine is decreasing in several countries and banned in other countries (Cheng et al., 2012; Garcia-Migura et al., 2014).

This study showed no clear association between the use of and resistance to a given antimicrobial. However, our sample size was relatively small, we were unable to determine recent antimicrobial use, and it was not possible to have a control farm because there are no farms in Jordan with no or minimal antimicrobial use. Nonetheless, our findings corroborate previous studies that did not find significant associations between antimicrobial use and resistance toward a named antimicrobial. Rather, antimicrobial use can be a contributing factor but probably not the main or single factor causing antimicrobial resistance (Bergman et al., 2009; Oliver et al., 2011). In our study, the reason why resistance did not correlate with use of an antibiotic could be that the animals selected had not received treatment in the previous 2 wk. Several other studies have found that the resistance induced by use is transient (Jiang et al., 2006; Lowrance et al., 2007; Checkley et al., 2008; Platt et al., 2008; Mann et al., 2011; Morley et al., 2011; Boyer and Singer, 2012). Moreover, because herdsmen choose antimicrobials based on experience, we assume that they would refrain from using antimicrobials with 
which they previously experienced a perceived treatment failure. Thus, an association between antimicrobial use and resistance might be difficult to detect.

\section{CONCLUSIONS}

Our research indicated that antimicrobials are misused in Jordanian dairies; specifically, antimicrobial agents are administered without a veterinary prescription and recommended withdrawal times are not adhered to. Furthermore, resistance among commensal $E$. coli toward antimicrobials of human and veterinary importance was high compared with that in other countries. To address this misuse and emerging resistance, it is essential to promote judicious use of antimicrobials in livestock operations, through educational programs for herdsmen and veterinarians conducted by the Ministry of Agriculture, veterinary association committees, and academic institutions. Immediate interventions that should be considered in Jordan include the use of costeffective and simple antimicrobial sensitivity testing before treating animals. Banning the use of critically important antibiotics for human health has been successfully implemented in several countries and should be considered in Jordan.

\section{ACKNOWLEDGMENTS}

This work was supported by Scientific Research Support Fund of the Jordan Ministry of Higher Education and Scientific Research (Project \# Agri 49).

\section{REFERENCES}

Alali, W. Q., H. M. Scott, B. Norby, W. Gebreyes, and G. H. Loneragan. 2009. Quantification of the bla(CMY-2) in feces from beef feedlot cattle administered three different doses of ceftiofur in a longitudinal controlled field trial. Foodborne Pathog. Dis. 6:917924 .

Alexander, T. W., G. D. Inglis, L. J. Yanke, E. Topp, R. R. Read, T. Reuter, and T. A. McAllister. 2010. Farm-to-fork characterization of Escherichia coli associated with feedlot cattle with a known history of antimicrobial use. Int. J. Food Microbiol. 137:40-48.

Asai, T., K. Harada, K. Ishihara, A. Kojima, T. Sameshima, Y. Tamura, and T. Takahashi. 2007. Association of antimicrobial resistance in Campylobacter isolated from food-producing animals with antimicrobial use on farms. Jpn. J. Infect. Dis. 60:290-294.

Bergman, M., S. T. Nyberg, P. Huovinen, P. Paakkari, and A. J. Hakanen. 2009. Association between antimicrobial consumption and resistance in Escherichia coli. Antimicrob. Agents Chemother. 53:912-917.

Bialek, S., J. P. Lavigne, J. Chevalier, E. Marcon, V. Leflon-Guibout, A. Davin, R. Moreau, J. M. Pages, and M. H. Nicolas-Chanoine. 2010. Membrane efflux and influx modulate both multidrug resistance and virulence of Klebsiella pneumoniae in a Caenorhabditis elegans model. Antimicrob. Agents Chemother. 54:4373-4378.

Bischoff, K. M., D. G. White, P. F. McDermott, S. Zhao, S. Gaines, J. J. Maurer, and D. J. Nisbet. 2002. Characterization of chloramphenicol resistance in beta-hemolytic Escherichia coli associated with diarrhea in neonatal swine. J. Clin. Microbiol. 40:389-394.
Blake, D. P., R. W. Humphry, K. P. Scott, K. Hillman, D. R. Fenlon, and J. C. Low. 2003. Influence of tetracycline exposure on tetracycline resistance and the carriage of tetracycline resistance genes within commensal Escherichia coli populations. J. Appl. Microbiol. 94:1087-1097.

Boyer, T. C., and R. S. Singer. 2012. Quantitative measurement of $b l a_{\mathrm{CMY}-2}$ in a longitudinal observational study of dairy cattle treated with ceftiofur. Foodborne Pathog. Dis. 9:1022-1027.

Brunton, L. A., H. E. Reeves, L. C. Snow, and J. R. Jones. 2014. A longitudinal field trial assesing the impact of feeding waste milk containing antibiotic residues on the prevalence of ESBL-producing Escherichia coli in calves. Prev. Vet. Med. 117:403-412.

Checkley, S. L., J. R. Campbell, M. Chirino-Trejo, E. D. Janzen, and J. J. McKinnon. 2008. Antimicrobial resistance in generic fecal Escherichia coli obtained from beef cattle on arrival at the feedlot and prior to slaughter, and associations with volume of total individual cattle antimicrobial treatments in one western Canadian feedlot. Can. J. Vet. Res. 72:101-108.

Cheng, A. C., J. Turnidge, P. Collignon, D. Looke, M. Barton, and T. Gottlieb. 2012. Control of fluoroquinolone resistance through successful regulation, Australia. Emerg. Infect. Dis. 18:1453-1460.

Chopra, I., and M. Roberts. 2001. Tetracycline antibiotics: Mode of action, applications, molecular biology, and epidemiology of bacterial resistance. Microbiol. Mol. Biol. Rev. 65:232-260.

CIPARS (Canadian Integrated Program for Antimicrobial Resistance Surveillance). 2013. Annual Report. Vol. 2016. Public Health Agency of Canada, Ottawa, ON, Canada.

CLSI. 2014. Performance standards for antimicrobial susceptibility testing. CLSI document M100-S24. Clinical and Laboratory Standards Institute (CLSI), Wayne, PA.

DANMAP (Danish Integrated Antimicrobial Resistance Monitoring and Research Programme). 2014. Use of antimicrobial agents and occurrence of antimicrobial resistance in bacteria from food animals, foods and humans in Denmark. Danish Institute for Food and Veterinary Research, Copenhagen.

Deeks, J. J., and J. P. T. Higgins. 2010. Statistical algorithms in Review Manager 5. Accessed Oct. 15, 2017. http://training.cochrane .org/handbook/statistical-methods-revman5.

DeFrancesco, K. A., R. N. Cobbold, D. H. Rice, T. E. Besser, and D. D. Hancock. 2004. Antimicrobial resistance of commensal Escherichia coli from dairy cattle associated with recent multi-resistant salmonellosis outbreaks. Vet. Microbiol. 98:55-61.

DoS (Department of Statistics). 2015. Agriculture surveys: Livestock production value and quantity. Accessed Aug. 13, 2016. http:// www.dos.gov.jo/owa-user/owa/FOCAL_AGR_anm.show_param $? \mathrm{LANG}=\mathrm{E} \& \operatorname{dis}=5$.

Duse, A., K. P. Waller, U. Emanuelson, H. E. Unnerstad, Y. Persson, and B. Bengtsson. 2013. Farming practices in Sweden related to feeding milk and colostrum from cows treated with antimicrobials to dairy calves. Acta Vet. Scand. 55:49.

Duse, A., K. P. Waller, U. Emanuelson, H. E. Unnerstad, Y. Persson, and B. Bengtsson. 2015. Risk factors for quinolone-resistant Escherichia coli in feces from preweaned dairy calves and postpartum dairy cows. J. Dairy Sci. 98:6387-6398.

ECDC (European Centre for Disease Prevention and Control). 2015. ECDC/EFSA/EMA first joint report on the integrated analysis of the consumption of antimicrobial agents and occurrence of antimicrobial resistance in bacteria from humans and food-producing animals. EFSA J. 13:4006.

Eltayb, A., S. Barakat, G. Marrone, S. Shaddad, and C. Stalsby Lundborg. 2012. Antibiotic use and resistance in animal farming: A quantitative and qualitative study on knowledge and practices among farmers in Khartoum, Sudan. Zoonoses Public Health 59:330-338.

European Food Safety Authority (EFSA). 2008. Harmonised monitoring of antimicrobial resistance in Salmonella and Campylobacter isolates from food animals in the European Union. Clin. Microbiol. Infect. 14:522-533.

FDA-CVM (Food and Drug Administration-Center for Veterinary Medicine). 2015. NADA 141-077: ADSPEC ${ }^{\mathrm{TM}}$ Sterile Solutionoriginal approval. Accessed Sep. 29, 2017. https://www.fda.gov/ 
AnimalVeterinary/Products/ApprovedAnimalDrugProducts / FOIADrugSummaries/ucm116789.htm.

FDA-DHHS (Food and Drug Administration-Department of Health and Human Services). 2012. New Animal Drugs; Cephalosporin Drugs; Extralabel Animal Drug Use; Order of Prohibition. https://www.federalregister.gov/documents/2012/01/06/2012-35/ new-animal-drugs-cephalosporin-drugs-extralabel-animal-drug-use -order-of-prohibition.

File, T. M., A. Srinivasan, and J. G. Bartlett. 2014. Antimicrobial stewardship: Importance for patient and public health. Clin. Infect. Dis. 59:S93-S96.

Friedman, N. D., E. Temkin, and Y. Carmeli. 2016. The negative impact of antibiotic resistance. Clin. Microbiol. Infect. 22:416-422.

Galvão, K. N. 2012. Postpartum uterine diseases in dairy cows. Anim. Reprod. 9:290-296.

Garcia-Migura, L., R. S. Hendriksen, L. Fraile, and F. M. Aarestrup. 2014. Antimicrobial resistance of zoonotic and commensal bacteria in Europe: The missing link between consumption and resistance in veterinary medicine. Vet. Microbiol. 170:1-9. https://doi.org/10 .1016/j.vetmic.2014.01.013.

Gonzalez, S. M., A. Steiner, B. Gassner, and G. Regula. 2010. Antimicrobial use in Swiss dairy farms: Quantification and evaluation of data quality. Prev. Vet. Med. 95:50-63.

Hao, H., G. Cheng, Z. Iqbal, X. Ai, H. I. Hussain, L. Huang, M. Dai, Y. Wang, Z. Liu, and Z. Yuan. 2014. Benefits and risks of antimicrobial use in food-producing animals. Front. Microbiol. 5:288. https://doi.org/10.3389/fmicb.2014.00288.

Harada, K., and T. Asai. 2010. Role of antimicrobial selective pressure and secondary factors on antimicrobial resistance prevalence in Escherichia coli from food-producing animals in Japan. J. Biomed. Biotechnol. 2010:180682.

Harada, K., T. Asai, A. Kojima, K. Ishihara, and T. Takahashi. 2006. Role of coresistance in the development of resistance to chloramphenicol in Escherichia coli isolated from sick cattle and pigs. Am. J. Vet. Res. 67:230-235.

Jiang, X., H. Yang, B. Dettman, and M. P. Doyle. 2006. Analysis of fecal microbial flora for antibiotic resistance in ceftiofur-treated calves. Foodborne Pathog. Dis. 3:355-365.

Kaesbohrer, A., A. Schroeter, B. A. Tenhagen, K. Alt, B. Guerra, and B. Appel. 2012. Emerging antimicrobial resistance in commensal Escherichia coli with public health relevance. Zoonoses Public Health 59:158-165.

Karczmarczyk, M., C. Walsh, R. Slowey, N. Leonard, and S. Fanning. 2011. Molecular characterization of multidrug-resistant Escherichia coli isolates from Irish cattle farms. Appl. Environ. Microbiol. 77:7121-7127.

Landers, T. F., B. Cohen, T. E. Wittum, and E. L. Larson. 2012. A review of antibiotic use in food animals: Perspective, policy, and potential. Public Health Rep. 127:4-22.

Leverstein-van Hall, M. A., C. M. Dierikx, J. Cohen Stuart, G. M. Voets, M. P. van den Munckhof, A. van Essen-Zandbergen, T. Platteel, A. C. Fluit, N. van de Sande-Bruinsma, J. Scharinga, M. J. Bonten, and D. J. Mevius. 2011. Dutch patients, retail chicken meat and poultry share the same ESBL genes, plasmids and strains. Clin. Microbiol. Infect. 17:873-880.

Lim, S. K., H. S. Lee, H. M. Nam, Y. S. Cho, J. M. Kim, S. W. Song, Y. H. Park, and S. C. Jung. 2007. Antimicrobial resistance observed in Escherichia coli strains isolated from fecal samples of cattle and pigs in Korea during 2003-2004. Int. J. Food Microbiol. 116:283-286.

Love, D. C., M. F. Davis, A. Bassett, A. Gunther, and K. E. Nachman. 2011. Dose imprecision and resistance: free-choice medicated feeds in industrial food animal production in the United States. Environ. Health Perspect. 119:279-283.

Lowrance, T. C., G. H. Loneragan, D. J. Kunze, T. M. Platt, S. E. Ives, H. M. Scott, B. Norby, A. Echeverry, and M. M. Brashears. 2007. Changes in antimicrobial susceptibility in a population of Escherichia coli isolated from feedlot cattle administered ceftiofur crystalline-free acid. Am. J. Vet. Res. 68:501-507.

Luna-Tortos, C., M. Correa, H. Cedeno-Guerra, and M. Caballero. 2006. Estudio sobre los patronesmde uso de antibioticos y los fac- tores de relevancia en el surgimiento de la resistencia bacteriana en fincas lecheras artesanales de Costa Rica. Cienc. Vet. 24:151-165.

Lundin, J. I., D. A. Dargatz, B. A. Wagner, J. E. Lombard, A. E. Hill, S. R. Ladely, and P. J. Fedorka-Cray. 2008. Antimicrobial drug resistance of fecal Escherichia coli and Salmonella spp. isolates from United States dairy cows. Foodborne Pathog. Dis. 5:7-19.

Magiorakos, A. P., A. Srinivasan, R. B. Carey, Y. Carmeli, M. E. Falagas, C. G. Giske, S. Harbarth, J. F. Hindler, G. Kahlmeter, B. Olsson-Liljequist, D. L. Paterson, L. B. Rice, J. Stelling, M. J. Struelens, A. Vatopoulos, J. T. Weber, and D. L. Monnet. 2012. Multidrug-resistant, extensively drug-resistant and pandrug-resistant bacteria: An international expert proposal for interim standard definitions for acquired resistance. Clin. Microbiol. Infect. $18: 268-281$.

Maheux, A. F., F. J. Picard, M. Boissinot, L. Bissonnette, S. Paradis, and M. G. Bergeron. 2009. Analytical comparison of nine PCR primer sets designed to detect the presence of Escherichia coli/ Shigella in water samples. Water Res. 43:3019-3028.

Mann, S., J. D. Siler, D. Jordan, and L. D. Warnick. 2011. Antimicrobial susceptibility of fecal Escherichia coli isolates in dairy cows following systemic treatment with ceftiofur or penicillin. Foodborne Pathog. Dis. 8:861-867.

Maron, D. F., T. J. Smith, and K. E. Nachman. 2013. Restrictions on antimicrobial use in food animal production: an international regulatory and economic survey. Global. Health 9:48.

Marshall, B. M., and S. B. Levy. 2011. Food animals and antimicrobials: Impacts on human health. Clin. Microbiol. Rev. 24:718-733.

Merle, R., M. Robanus, C. Hegger-Gravenhorst, Y. Mollenhauer, P. Hajek, A. Käsbohrer, W. Honscha, and L. Kreienbrock. 2014. Feasibility study of veterinary antibiotic consumption in GermanyComparison of ADDs and UDDs by animal production type, antimicrobial class and indication. BMC Vet. Res. 10:7.

Mirzaagha, P., M. Louie, R. Sharma, L. J. Yanke, E. Topp, and T. A. McAllister. 2011. Distribution and characterization of ampicillinand tetracycline-resistant Escherichia coli from feedlot cattle fed subtherapeutic antimicrobials. BMC Microbiol. 11:78.

Morley, P. S., D. A. Dargatz, D. R. Hyatt, G. A. Dewell, J. G. Patterson, B. A. Burgess, and T. E. Wittum. 2011. Effects of restricted antimicrobial exposure on antimicrobial resistance in fecal Escherichia coli from feedlot cattle. Foodborne Pathog. Dis. 8:87-98.

NARMS (National Antimicrobial Resistance Monitoring System). 2015. The 2012-2013 Integrated NARMS Report. USDA, Beltsville, MD

NORM/NORM-VET. 2010. Report on usage of antimicrobial agents and occurrence of antimicrobial resistance in Norway in animals and humans. Vol. 2015. National Veterinary Institute, Oslo, Norway.

OIE (World Organization for Animal Health). 2015. OIE list of antimicrobials of veterinary importance. OIE, Paris, France.

Oliver, S. P., S. E. Murinda, and B. M. Jayarao. 2011. Impact of antibiotic use in adult dairy cows on antimicrobial resistance of veterinary and human pathogens: A comprehensive review. Foodborne Pathog. Dis. 8:337-355.

Pagano, M., and K. Gauvreau. 2000. Principles of Biostatistics. 2nd ed. Brooks/Cole, Belmont, CA.

Pardon, B., B. Catry, J. Dewulf, D. Persoons, M. Hostens, K. De Bleecker, and P. Deprez. 2012. Prospective study on quantitative and qualitative antimicrobial and anti-inflammatory drug use in white veal calves. J. Antimicrob. Chemother. 67:1027-1038.

Parveen, S., J. Lukasik, T. M. Scott, M. L. Tamplin, K. M. Portier, S. Sheperd, K. Braun, and S. R. Farrah. 2006. Geographical variation in antibiotic resistance profiles of Escherichia coli isolated from swine, poultry, beef and dairy cattle farm water retention ponds in Florida. J. Appl. Microbiol. 100:50-57.

Platt, T. M., G. H. Loneragan, H. M. Scott, B. Norby, D. U. Thomson, M. S. Brown, S. E. Ives, and M. M. Brashears. 2008. Antimicrobial susceptibility of enteric bacteria recovered from feedlot cattle administered chlortetracycline in feed. Am. J. Vet. Res. 69:988-996.

Redding, L. E., F. Cubas-Delgado, M. D. Sammel, G. Smith, D. T. Galligan, M. Z. Levy, and S. Hennessy. 2014. The use of antibiotics on small dairy farms in rural Peru. Prev. Vet. Med. 113:88-95. 
RESAPATH. 2012. Monitoring of Antimicrobial Resistance in Pathogenic Bacteria in Animals in France in 2012: Summary Report of the RESAPATH network (French surveillance network for antimicrobial resistance in pathogenic bacteria of animal origin). RESAPATH, Maisons-Alfort, France.

Roderick, S., P. Stevenson, C. Mwendia, and G. Okech. 2000. The use of trypanocides and antibiotics by Maasai pastoralists. Trop. Anim. Health Prod. 32:361-374.

Sawant, A. A., L. M. Sordillo, and B. M. Jayarao. 2005. A survey on antibiotic usage in dairy herds in Pennsylvania. J. Dairy Sci. 88:2991-2999.

Sayah, R. S., J. B. Kaneene, Y. Johnson, and R. Miller. 2005. Patterns of antimicrobial resistance observed in Escherichia coli isolates obtained from domestic- and wild-animal fecal samples, human septage, and surface water. Appl. Environ. Microbiol. 71:13941404.

Smith, G. W., R. Gehring, A. L. Craigmill, A. I. Webb, and J. E. Riviere. 2005. Extralabel intramammary use of drugs in dairy cattle. J. Am. Vet. Med. Assoc 226:1994-1996.

Spiegel, M., P. Sterrenburg, W. Haasnoot, and H. J. van der FelsKlerx. 2013. Towards a decision support system for control of multiple food safety hazards in raw milk production. Trends Food Sci. Technol. 34:137-145.
SWEDRES/SWEDVARM. 2014. Consumption of antibiotics and occurrence of antibiotic resistance in Sweden. J. Hellman, O. Aspevall, B. Bengtsson, and M. Pringle, ed. Public Health Agency of Sweden and National Veterinary Institute, Stockholm, Sweden.

Teshager, T., I. A. Herrero, M. C. Porrero, J. Garde, M. A. Moreno, and L. Dominguez. 2000. Surveillance of antimicrobial resistance in Escherichia coli strains isolated from pigs at Spanish slaughterhouses. Int. J. Antimicrob. Agents 15:137-142.

Tragesser, L. A., T. E. Wittum, J. A. Funk, P. L. Winokur, and P. J. Rajala-Schultz. 2006. Association between ceftiofur use and isolation of Escherichia coli with reduced susceptibility to ceftriaxone from fecal samples of dairy cows. Am. J. Vet. Res. 67:1696-1700.

White, D. G., C. Hudson, J. J. Maurer, S. Ayers, S. Zhao, M. D. Lee, L. Bolton, T. Foley, and J. Sherwood. 2000. Characterization of chloramphenicol and florfenicol resistance in Escherichia coli associated with bovine diarrhea. J. Clin. Microbiol. 38:4593-4598.

WHO (World Health Organization). 2012. Critically important antimicrobials for human medicine; 3rd Revision. WHO, Geneva, Switzerland.

WHO (World Health Organization). 2014. Antimicrobial resistance: Global report on surveillance. Accessed Sep. 9, 2017. http://apps .who.int/iris/bitstream/10665/112642/1/9789241564748_eng.pdf $?$ ua $=1$. 